\title{
An experimental approach to the effects of varying recruitment strategy and food intake on early reproductive traits in a brooding Mediterranean polychaete
}

\author{
D. Martin ${ }^{1, *}$, J. H. Cha ${ }^{2}$, C. Nozais ${ }^{3}$, M. Bhaud ${ }^{3}$ \\ ${ }^{1}$ Centre d'Estudis Avançats de Blanes (CSIC), Camí de Santa Bàrbara s/n, E-17300 Blanes (Girona), Spain \\ ${ }^{2}$ KORDI (Korea Ocean Research and Development Institute), Biological Oceanography Division, ANSAN PO Box 29, \\ Seoul Kr-425-600, Korea \\ ${ }^{3}$ Laboratoire Arago, Observatoire Océanologique de Banyuls, Université P. et M. Curie (Paris VI), CNRS, URA 117, \\ F-66651 Banyuls-sur-Mer cedex, France
}

\begin{abstract}
We examined the effects of reproductive strategy and food intake on the early life history traits of a Mediterranean population of Eupolymnia nebulosa, a deposit-feeding, tubicolous polychaete. In the Mediterranean E. nebulosa are brood-caring, maturity is attained at 2 y and up to 4 cocoons are produced per female each year, which reduces larval dispersal. In the Atlantic E. nebulosa are freespawning, they mature in their first year of life and they produce larger offspring, which are released simultaneously. An experimental population grown from spawn collected in the Mediterranean was divided into 2 groups on the basis of the number of tentacles. These 2 groups were taken to simulate the 2 reproductive strategies: worms with 2, 3, 4 and 5 tentacles at the start for the Mediterranean strategy and worms with 3 tentacles at the start for the Atlantic strategy. They were further subdivided and treated with low-and high-energy diets. After 3 mo the only significant difference was a high number of survivors in the group used to simulate Mediterranean recruitment. After 12 mo the high-energy diet increased survival, mean number of tentacles per individual, total tentacles and total worm biomass, and reduced generation time to $1 \mathrm{yr}$. Although fecundity of these early breeders was lower than that of 2 yr old worms from both laboratory and field populations, this can be entirely attributed to differences in maternal body size. Based on our experimental results, the ecological implications of the reproductive strategy of Mediterranean E. nebulosa are discussed and a new model of resource allocation is proposed for their populations
\end{abstract}

KEY WORDS: Terebellidae Eupolymnia nebulosa. Recruitment strategy Food intake. Early reproductive traits NW Mediterranean

\section{INTRODUCTION}

An organism's intake of resources is determined by its ability to forage, while its life history patterns (growth, survival, reproduction) are a reflection of resource expenditure on fitness-related activities. In a limited pool, the allocation of resources provides an inextricable link between these foraging and life history strategies (Boggs 1992). Thus, in a given environment, organisms compete by consuming a scarce

•E-mail: dani@ceab.csic.es resource or by controlling access to it (Keddy 1989), and so resource availability and allocation may affect the life history of individuals and the demographic characteristics of whole populations (Boggs 1992). In certain environments, moreover, one ecotype might eventually replace another (Ricklefs 1991) and it has been hypothesised that this might have occurred in the case of Eupolymnia nebulosa (Montagu).

This terebellid polychaete has been reported on the European Atlantic and Mediterranean coasts (see Fig. 1A). It is believed that the Mediterranean populations are descended from the Atlantic ones (Bhaud et 


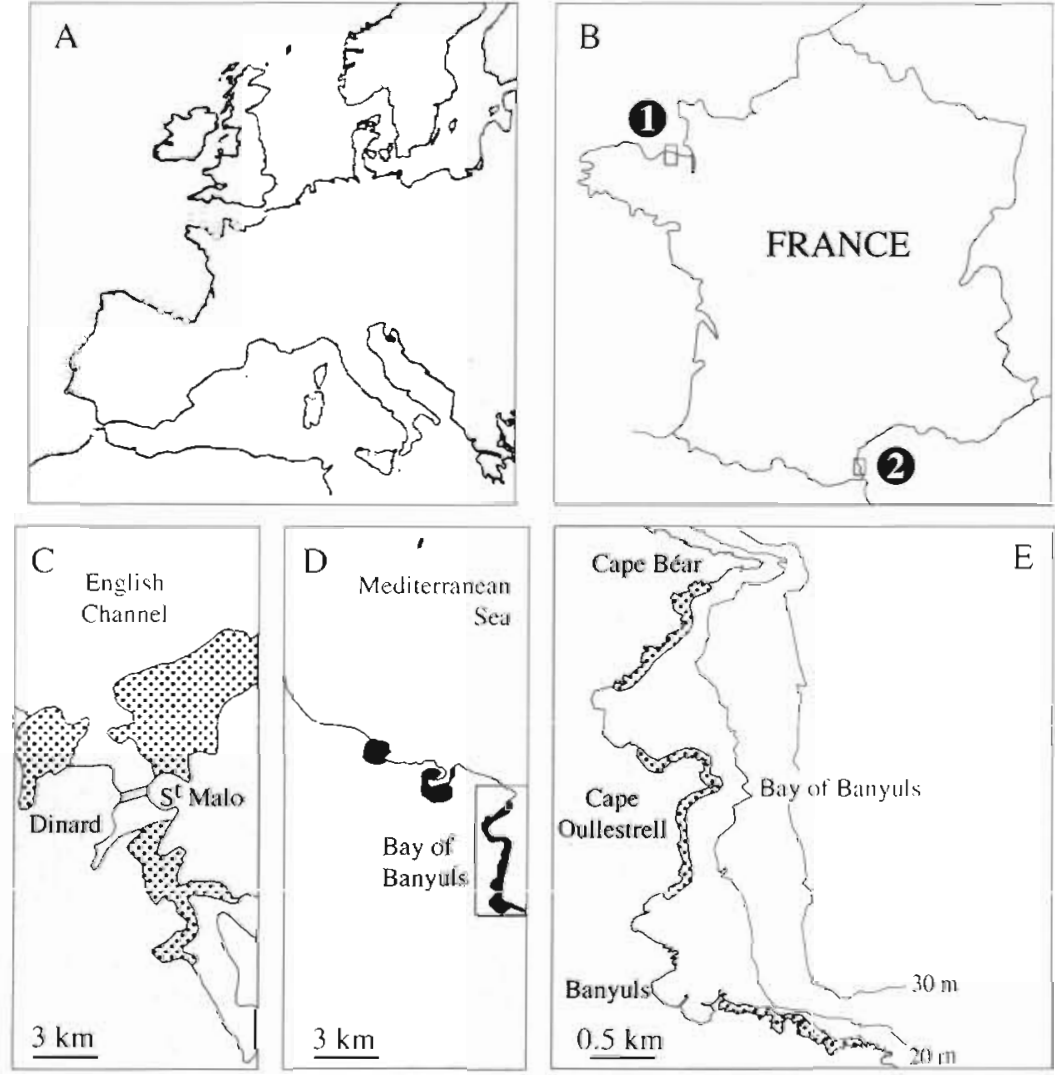

Fig. 1. (A) Records of Eupolymnia nebulosa on European shores (white circles; modified from Lang 1986). (B) Geographical locations of (1) the Rance Estuary (English Channel) and (2) the Bay of Banyuls. (C) Extent of area inhabited by $E$. nebulosa on the Rance Estuary shores (dotted area). (D) Mediterranean records of E. nebulosa near the Bay of Banyuls (black area). (E) Extent of area of coastal belts inhabited by $E$. nebulosa on Bay of Banyuls shores (dotted area) giving rise to a homogeneous cohort of juveniles (Lang 1984, 1986, Grémare 1986, Bhaud et al. 1987, 1995). In the less dense populations of the Mediterranean, in contrast, spawning occurs in jelly egg-masses. Four or five peaks in egg-mass production have been recorded between March and early June, with each female producing up to 4 egg-masses (Duchêne \& Nozais 1992, Bhaud et al. 1995, Nozais et al. 1997). As in Atlantic populations, a homogeneous cohort of juveniles joins the adult populations at the end of the period of settlement. However, it has been suggested that in the Mediterranean this is accomplished by the recruitment of successive pseudocohorts, each group growing at a faster rate than the previous one in response to increasing temperature (Bhaud et al. 1995). However, the overall clutch size seems to be smaller in Mediterranean populations (authors' unpubl. data). In these populations the age at first maturity is reported to be 2 yr (Grémare 1988), while in Atlantic populations it is $1 \mathrm{yr}$ (Lang 1986).

In the Mediterranean, after release from the egg-mass, the Eupolymnia nebulosa larvae preferably settle on a fine layer of sediments. The sediments facilitate the construction of a tube, al. 1995). The species is an obligatory tubicolous worm found in areas of mixed hard and soft substrata. This particular environment occurs in markedly different areas. Thus, in Mediterranean sites, such as the Bay of Banyuls (Guille 1970, authors' pers. obs.), it is found in narrow belts in shallow water (see Fig. 1D, E); while, in the Atlantic sites, such as the Rance Estuary (Lang 1984, 1986), it occupies more extensive areas (see Fig. 1C). Furthermore, Atlantic habitats are reported to have higher carrying capacities than their Mediterranean counterparts (Ketchum 1983, Tuvia 1983, BenPérès 1985)

The life cycles of the Atlantic and Mediterranean populations of Eupolymnia nebulosa are markedly different. Yet, the extent to which these differences are genetically or environmentally determined remains unclear (Grémare 1986, Lenaers \& Bhaud 1992, Martin et al. 1996). The denser populations of the Atlantic are free-spawning, with egg laying occurring in one short event, following which the free-living planktonic larvae settle simultaneously in the adult habitat, so which the larva attaches to the subjacent hard substrate thereby preventing its hydrodynamic erosion (Cha et al. 1991, Bhaud \& Cha 1994, Cha 1994). However, as the energy requirement for growth rapidly exceeds that provided by yolk reserves, juvenile worms have to combine tube building with foraging activities. Initially, juveniles explore the surface by elongating the tube, but after a month they begin to explore the surface at a distance of more than 1 tube length. This indicates that the tentacles become increasingly more functional, and consequently there is a marked decrease in the tube-building material requirements around the 3 -tentacle stage (Cha 1994).

As Eupolymnia nebulosa is a surface deposit feeder, the sediment collected with the help of tentacles constitutes the sole source of food (Lang 1984). In the typical Mediterranean habitat, however, sediments are scarce and patchy, and so adults with numerous long tentacles may impede the access of juveniles to these particles (Cha 1994). In addition, recruits from successive pseudocohorts differ in their number of tentacles (authors' pers. 
obs.), and so competition for food may also occur after settling and prior to joining the adult population.

This study was designed to explain how food intake and reproductive strategy are related. It combines (1) a simulation of the reproductive strategies of the Mediterranean and Atlantic populations of Eupolymnia nebulosa (i.e. recruitment of several successive pseudo-cohorts and single recruitment, respectively) on the basis of the number of tentacles of newly hatched Mediterranean offspring; and (2) a simulation of the low and high carrying capacities of the Mediterranean and Atlantic habitats. The results of these simulated conditions are then analysed to assess their influence on the main traits of the early life history of the species (growth, survival, age at maturity and number of offspring)

\section{MATERIAL AND METHODS}

All juvenile Eupolymnia nebulosa specimens came from the same egg-mass (to avoid inter-individual genetic variability) spawned in March 1994 and collected by SCUBA diving at a depth of $7 \mathrm{~m}$ in the Bay of Banyuls, France (NW Mediterranean) (Fig. 1). This egg-mass was transported to the laboratory in a plastic bag and deposited in a tank $(50 \times 40 \times 30 \mathrm{~cm})$ with native seawater into which the larvae were released. To facilitate settlement, a fine layer of natural sediment collected from the Nephtys hombergii community of the Bay was sieved through a $60 \mu \mathrm{m}$ pore sieve and added to the tank. Postlarvae were fed once a week for 1 mo with Tetramin ${ }^{\circledR}$ food and their health (i.e. appearance of tegument, colour, body and tentacle motility, tube-building ability) was carefully checked prior to beginning the experiments. The experiments were conducted in a number of small tanks (1 l) arranged in a flow-through system $\left(11.5 \pm 2.0 \mathrm{l} \mathrm{h}^{-1}\right.$ of water renewal). Prior to being added to the tanks, seawater from a reservoir (where large particles were deposited) was passed through an Eheim external filter containing only synthetic fibres (mechanical filtration).

Worms were fed on either low-or high-energy diets. The use of natural sediment from the Nephtys hombergii community allowed us to simulate the low carrying capacity of the Mediterranean habitat in one treatment. In this diet (the low-energy diet), worms received only an initial input of natural sediment and, then, only the finest natural particulate material reached the tanks during the experiment in the filtered water supply. In the other diet (high-energy), food was increased to levels similar to those found in natural Atlantic (Rance Estuary, English Channel) sediments ( $6.9 \pm 0.42 \mathrm{mg} \mathrm{C} \mathrm{g}^{-1}$ sediment). In this diet, worms received an initial input of the natural sediment from the Nephtys hombergii community of the Bay of Banyuls and, then, a weekly input of $5 \mathrm{mg}$ of Tetramin $\otimes$ food $\left(0.46 \pm 0.13 \mathrm{mg} \mathrm{C} \mathrm{mg}^{-1}\right.$ food). The initial conditions were: $3.83 \pm 0.33 \mathrm{mg} \mathrm{C} \mathrm{g}^{-1}$ sediment in the lowenergy diet ( $24 \mathrm{~h}$ after sediment release into the tanks, polychaetes absent) and $6.38 \pm 0.94 \mathrm{mg} \mathrm{C} \mathrm{g}^{-1}$ sediment in the high-energy diet ( $24 \mathrm{~h}$ after sediment and Tetramin ${ }^{(1)}$ release into the tanks, polychaetes absent.). The experiment was designed to allow all remaining environmental variables (viz. photoperiod, temperature) to follow their normal variability in all tanks.

One-month-old juveniles were selected according to the number of tentacles (NT). This criterion was chosen because tentacles are the only tool available to this deposit-feeding species for collecting sediment (and therefore food) and, also, because: (1) NT can be easily determined without damage to live worms; (2) NT is not fixed and may respond to the environmental conditions (mainly food availability); (3) it is possible to infer from this datum the particle collection effort that sediments can support; and (4) NT can easily be applied to studies of natural or experimental populations (Lang 1984, Bhaud et al. 1995). Prior to determination of NT, worms were gently anaesthetised using MS222 (tricaine methanous sulphide). Then, they were maintained for $24 \mathrm{~h}$ in filtered seawater and returned to the experimental tanks.

The 2 reproductive strategies (i.e. recruitment of several successive pseudo-cohorts in the Mediterranean and single recruitment in the Atlantic) were also simulated. The simulation of the Mediterranean strategy was conducted with 20 juveniles per tank comprising 5 worms with 2 tentacles, 5 with 3 tentacles, 5 with 4 tentacles and 5 with 5 tentacles; whereas the Atlantic strategy was conducted with 20 juveniles per tank, comprising worms whose NT was the same as the mean for the entire sample (i.e. 3 tentacles). Three replicates of each simulated recruitment strategy were placed on each of the 2 different diets, and the corresponding experimental tanks ( $n=12$ ) were then interspersed.

Three months $\left(t_{3}\right.$; i.e. the end of the current spawning period) and 1 year $\left(t_{12}\right)$ after starting the experiments, we estimated the number of survivors, the mean individual NT, and the increase in the total tentacles in each tank as a measure of the food-collecting effort (NT $t_{i} / \mathrm{NT} t_{0}$, where NT $t_{0}$ is the initial sum NT for all worms, and NT $t_{1}$ is the total NT at either $t_{3}$ or $t_{12}$ ). At $t_{12}$, we calculated 2 female postparturition biomass indexes (total biomass in each tank and mean individual biomass) and 2 measurements of sediment organic content (total matter and carbon percentages). Female postparturition biomass was measured as ash-free dry weight (AFDW; $24 \mathrm{~h}$ at $60^{\circ} \mathrm{C}, 3 \mathrm{~h}$ at $450^{\circ} \mathrm{C}$ ). Total organic matter in the sediment was calculated as weight loss after ashing $\left(24 \mathrm{~h}\right.$ at $60^{\circ} \mathrm{C}, 3 \mathrm{~h}$ at $\left.450^{\circ} \mathrm{C}\right)$. Organic 
carbon was calculated following the standardised procedure described by Buscail et al. (1995).

When females laid eggs in the experimental conditions, we recorded the number of egg-masses produced in each tank. After disaggregating the mucous egg-masses by shaking, the number of eggs per cocoon was counted using graded dishes. Egg-mass volume was calculated as the displacement produced in a known volume of seawater. We also calculated the egg-mass volume and the egg number per cocoon in relation to the female postparturition biomass.

Cocoons from the natural population of the Bay of Banyuls and from a laboratory culture (established in 1992 in tanks simulating the Mediterranean carrying capacity) were collected on the same dates as those on which spawning occurred in the experimental conditions. For these 2 additional populations, we recorded the total clutch size (as total number of eggs from all egg-masses produced by a single female during the whole spawning period). Relative total clutch size (total clutch size/female postparturition biomass) was also calculated.

The experiment was concluded about $26 \mathrm{~d}$ after the last egg-mass was produced by the experimental population. Although successive peaks were observed in the natural population, no further spawning was observed in the experimental conditions. It was thus assumed that no additional spawning would occur in the experiment. The possible presence of coelomic gametes was then checked by dissection of previously anaesthetised worms. The number of oocytes per female was counted using graded dishes and the presence or absence of sperm noted. Following Stearns (1994), we considered those females effectively producing egg-masses in the experimental conditions to be at the age of their first sexual maturity.

Differences according to experimental times, strategies and diets were analysed by factorial analysis of variance (ANOVA) and Tukey's honestly significant difference (Tukey HSD) multiple comparisons test. Differences according to experimental strategies and diets in the variables measured only at $t_{12}$ were analysed by 2-way ANOVA and Tukey HSD multiple comparisons test. The relationships between the organic contents of the sediment and the variables measuring the responses of Eupolyminia nebulosa at $t_{12}$ were assessed by Pearson correlation analysis. Raw data and relative values (adjusted by female postparturition biomass) measuring the offspring of natural and laboratory populations were compared to those from the experimental populations by 1 -way ANOVA and by analysis of covariance using female postparturition biomass as covariate (ANCOVA), respectively. Variables were appropriately transformed so as to comply with the assumptions of the parametric tests.

\section{RESULTS}

The highest mortality occurred during the first 3 mo of the experiment, with about 95 and $89 \%$ of total mortality at $t_{12}$ occurring in the low-and high-energy diets, respectively, in this initial period (Fig, 2A). Therefore, the only significant changes in the number of individuals during the course of the experiment occurred between $t_{0}$ and $t_{3}$ (Tukey HSD, $p<0.0002$ ). Although the number of individuals always tended to be higher in the simulated Mediterranean recruitment
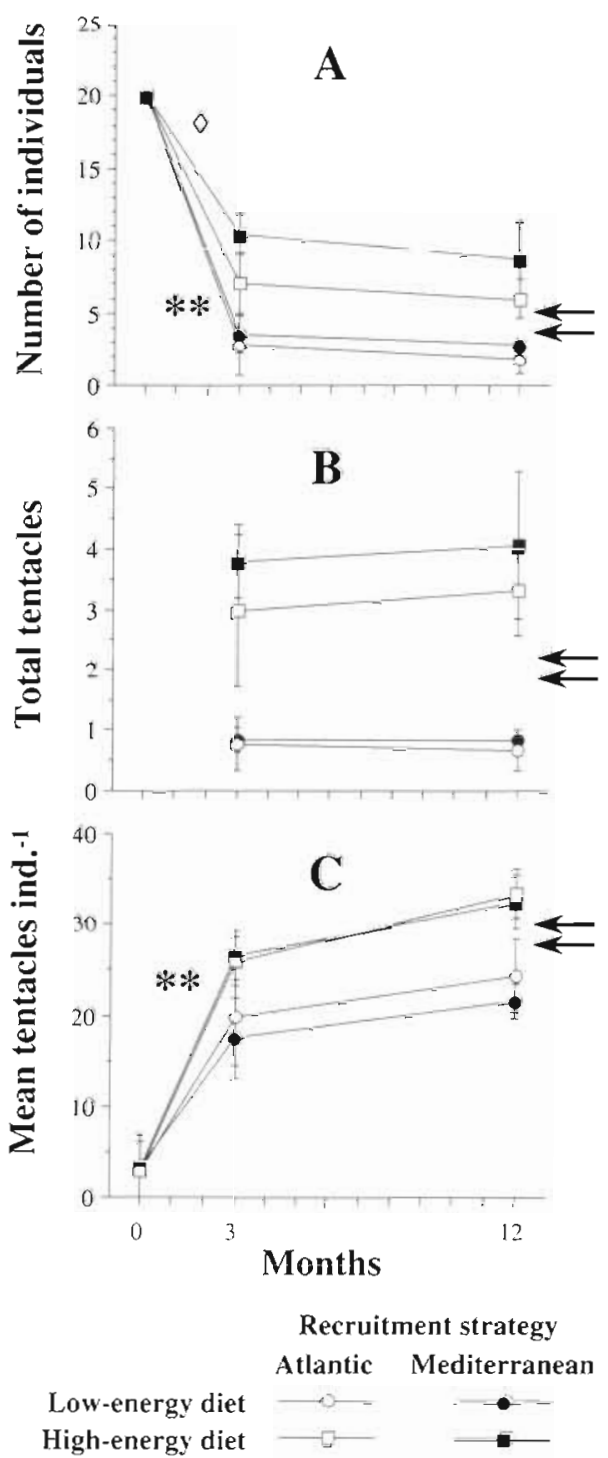

Fig. 2. Eupolymnia nebulosa. Time course of the variables describing worm populations raised under experimental diets and simulated recruitment strategies. (A) Number of individuals. (B) Total tentacles per tank (as a measure of foodcollecting effort). (C) Mean number of tentacles per individual. Diamonds, asterisks, and arrows indicate significant differences in recruitment strategies, time, and diets, respectively;

( 0$) 0.05 \geq p>0.001_{i}(\approx, * *) p \leq 0.001$ Vertical bars $\pm S D$ 
strategy than in the Atlantic one, this was only significant at $t_{3}$ (Tukey HSD, $\mathrm{p}<$ 0.0002). Moreover, there was a significant combined effect of time and diet, since there were twice as many individuals on the high-energy diet as on the lowenergy diet, both at $t_{3}$ and $t_{12}$ (Tukey HSD, $\mathrm{p} \leq 0.0001$ ).

The food-collecting effort (Fig. 2B) and the mean number of tentacles per individual (Fig. 2C) did not differ significantly between the 2 simulated recruitment strategies over time. The food-collecting effort showed a significant effect of diet, attributable to a greater effort in the high-energy than in the low-energy diet at each time. Although non-significant, the food-collecting effort tended to be similar or slightly lower at $t_{12}$ than at $t_{3}$ in the lowenergy diet and slightly higher at $t_{12}$ than at $t_{3}$ in the high-energy diet. The mean number of tentacles per individual showed a significant combined effect of time and diet, attributable to means for the low- and high-energy diets at $t_{3}$ which were non-significantly different from the mean for the low-energy diet at $t_{12}$ and significantly lower than the mean for the high-energy diet at $t_{12}$ (Tukey HSD, $\mathrm{p}<0.0002$ ).

Total and mean individual biomass of Eupolymnia nebulosa and sediment organic contents (i.e. total and carbon) at $t_{12}$ did not differ significantly between the 2 simulated recruitment strategies (Fig. 3). Both the total E. nebulosa biomass (Fig. 3A) and the organic carbon content (Fig. 3D) showed a significant effect of diet, the high-energy diet supporting a significantly higher biomass and containing more organic carbon

Table 1. Eupolymnia nebulosa. Reproductive characteristics of 1 yr old worms raised with the experimental diets and simulated recruitment strategies (i.e. Atlantic or Mediterranean). NMS: number of males with coelomic sperm in each tank; NFO: number of females with coelomic oocytes in each tanki Oocytes: mean number of coelomic oocytes per females in each tank; Cocoons: number of egg-masses produced in each tank. Values given as mean $\pm \mathrm{SD}$

\begin{tabular}{|c|c|c|c|c|}
\hline & \multirow{2}{*}{\multicolumn{2}{|c|}{$\begin{array}{l}\text { Low-energy diet } \\
\text { A.tlantic Mediterranean }\end{array}$}} & \multicolumn{2}{|c|}{ High-energy diet } \\
\hline & & & Atlantic & Mediterranean \\
\hline NMS & - & - & $2.25 \pm 0.96$ & $3.00 \pm 1.41$ \\
\hline $\mathrm{NFO}$ & $1.00 \pm 0.00$ & - & $3.75 \pm 0.96$ & $3.75 \pm 0.96$ \\
\hline Oocytes & $903 \pm 0$ & - & $1874 \pm 715$ & $1172 \pm 1182$ \\
\hline Cocoons & - & - & $2.67 \pm 0.58$ & $1.50 \pm 0.715$ \\
\hline
\end{tabular}

A
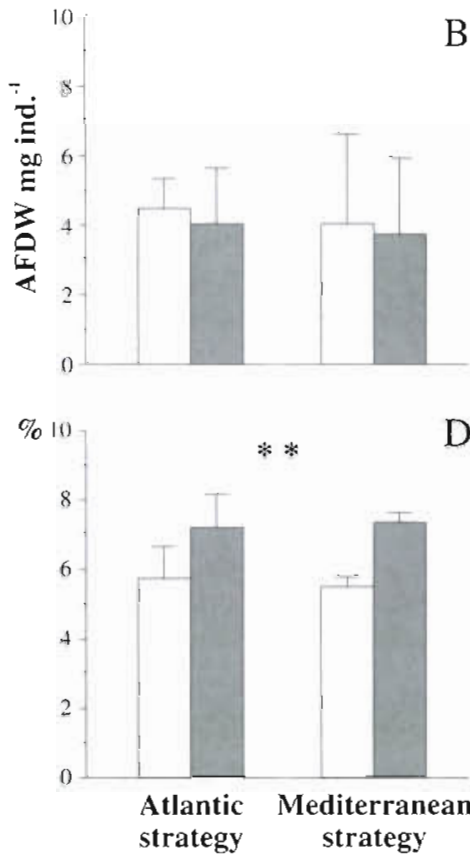

High-energy diet

Fig. 3. Eupolymnia nebulosa. Indexes of female postparturition biomass and (A) Total biomass in each tank. (B) Mean individual biomass. (C) Percentage of total organic matter in the sediment. (D) Percentage of organic carbon $(* *) p<0.001$ Vertical bars indicate $+\mathrm{SD}$

than the low-energy diet (Tukey HSD, $\mathrm{p}<0.008$ and $\mathrm{p}<0.004$, respectively). In contrast, neither the mean individual biomass (Fig. $3 \mathrm{~B}$ ) nor the total organic matter content (Fig. 3D) showed significant differences between diets. Moreover, the organic carbon content did not correlate significantly with the mean individual biomass ( $\mathrm{n}=16$; $\mathrm{r}=0.140$ ), but did with the number of survivors $(n=16 ; r=0.659, p<0.006)$, the mean number of tentacles per individual ( $\mathrm{n}=16 ; \mathrm{r}=0.724$, $\mathrm{p}=0.002)$, the food-collecting effort ( $\mathrm{n}=$ 16; $r=0.626, p<0.01)$ and the total biomass $(n=16 ; r=0.641, p<0.008$ ). However, the total organic matter content did not show any significant correlation with the number of survivors, mean number of tentacles per individual, food-collecting effort, mean individual biomass, and total biomass at $t_{12}(\mathrm{n}=$ 16; $r<0.06)$.

Table 1 illustrates the reproductive characteristics of Eupolymnia nebulosa raised on different diets. Effective reproduction (i.e. spawning into egg-masses) at $t_{12}$ occurred only in the high-energy diet. More than $70 \%$ of the 1 yr old 
Table 2. Eupolymnia nebulosa. Summary of the reproductive characteristics of breeding females from the experimental (early breeders), field (natural breeders) and laboratory (labokatory breeders) Mediterranean worm populations. Relative values are adjusted by female postparturition biomass. Raw data and relative values were analysed by 1 -way ANOVA and ANCOVA using female postparturition biomass as covariate, respectively; ns: non-significant differences among all breeders; $\cdots p \leq 0.001$

\begin{tabular}{|c|c|c|c|c|}
\hline & Early breeders & Laboratory breeders & Natural breeders & Signif. \\
\hline Date of first spawning & $16 \mathrm{Mar}$ to $10 \mathrm{Apr}$ & 1 Mar to 14 Apr & 8 Mar to 27 Apr & \\
\hline Age at spawning & $1 y r$ & $2 y r$ & At least 2 yr & \\
\hline \multicolumn{5}{|c|}{ Postparturition biomass (AFDW mg) } \\
\hline Mean \pm SD & $4.68 \pm 4.24$ & $28.18 \pm 12.23$ & $41.24 \pm 22.55$ & $\cdots$ \\
\hline Range & $1.80-16.80$ & $14.10-58.90$ & $13.10-73.20$ & \\
\hline \multicolumn{5}{|c|}{ Volume of first egg-mass $\{\mathrm{ml}\}$} \\
\hline Mean $\pm S D$ & $1.36 \pm 0.91$ & $8.09 \pm 3.61$ & $7.64 \pm 5.30$ & $\because$ \\
\hline Range & $0.50-3.00$ & $2.00-16.00$ & $3.20-18.60$ & \\
\hline \multicolumn{5}{|c|}{ Relative volume of first egg-mass } \\
\hline Mean $\pm \mathrm{SD}$ & $0.32 \pm 0.12$ & $0.35 \pm 0.29$ & $0.23 \pm 0.16$ & ns \\
\hline Range & $0.18-0.56$ & $0.07-1.14$ & $0.06-0.51$ & \\
\hline \multicolumn{5}{|c|}{ Egg number of first egg-mass } \\
\hline Mean \pm SD & $1702 \pm 1716$ & $12063 \pm 4127$ & $12175 \pm 11537$ & $\because$ \\
\hline Range & $126-4793$ & $4547-16900$ & $2800-37100$ & \\
\hline \multicolumn{5}{|c|}{ Relative egg number of first egg-mass } \\
\hline Mean $\pm \mathrm{SD}$ & $363 \pm 299$ & $492 \pm 241$ & $330 \pm 272$ & ns \\
\hline Range & $50-922$ & $132-1014$ & $90-975$ & \\
\hline \multicolumn{5}{|c|}{ Clutch size during the whole spawning poriod } \\
\hline Mean $\pm \mathrm{SD}$ & $1702 \pm 1716$ & $16516 \pm 6213$ & $15578 \pm 13641$ & $\because$ \\
\hline Range & $126-4793$ & $6967-29163$ & $2800-43450$ & \\
\hline \multicolumn{5}{|c|}{ Relative clutch size during the whole spawning period } \\
\hline Mean $\pm \mathrm{SD}$ & $363 \pm 299$ & $650 \pm 359$ & $414 \pm 323$ & ns \\
\hline Range & $50-922$ & $257-1618$ & $90-1199$ & \\
\hline
\end{tabular}

females from the simulated Atlantic and $40 \%$ of those from the Mediterranean recruitment strategy laid eggs (referred to as early breeders), each female producing only 1 egg-mass during the experiment. Consequently, this age will be used in future articles as the time of first reproduction for Mediterranean E. nebulosa. The remaining females fed on the high-energy diet had well-developed mucous glands and coelomic oocytes, indicating that they were physiologically able to reproduce. However, in contrast to early breeders, these females did not produce egg-masses during the experiment.

In the low-energy diet, only 2 females had coelomic gametes at $t_{12}$. However, these females had not developed mucous glands, indicating that they were not ready to produce egg-masses. Although sample sizes were too small for adequate statistical comparisons, females fed on the high-energy diet which did not produce egg-masses at $t_{12}$ (referred to as delayed breeders) had about 2.5 times more coelomic oocytes than those fed on the low-energy diet, even when correcting for differences in the maternal biomass.

The individual postparturition biomass of early breeders did not significantly differ from that of delayed breeders fed on both the high- and lowenergy diets. In contrast, significant differences were found when early breeders were compared with females from the laboratory culture simulating the Mediterranean carrying capacity (referred to as laboratory breeders) and from the natural population from the Bay of Banyuls (referred to as natural breeders), which laid cocoons (Table 2). Laboratory breeders were in their second year of life, and were up to 6 times larger than the early breeders. Although the age of natural breeders could not be assessed exactly, they must have been at least 2 yr old, and their postparturition biomass was up to 9 times greater than that of early breeders.

The early breeders from the simulated Atlantic recruitment strategy produced more cocoons than those from the Mediterranean (Table 1). However, neither mean egg-mass volume nor mean number of eggs per egg-mass (1.3 and $1.5 \mathrm{ml}$ and 1752 and 1571 eggs in the Atlantic and Mediterranean strategies, respectively) differed significantly. Therefore, they were pooled together for subsequent comparisons.

There were significant differences in the offspring produced by the various groups of breeders (Table 2). Early breeders had smaller egg-masses and a lower number of eggs per cocoon than laboratory and natural breeders at the same dates (i.e. first-spawned eggmasses) (Tukey HSD, $p<0.0002$ ), though these differ- 
ences were non-significant between laboratory and natural breeders (Table 2). In accordance with our methods outlined above, we may consider the single offspring produced by each early breeder as being the total clutch produced during the spawning period. However, comparisons between these clutches and total clutches for each laboratory and natural breeder led to little overall change in our results (Table 2), the differences being greater and more significant than those found with the first egg-masses of laboratory and natural breeders (Tukey HSD, $p<0.0001$ ). However, total clutches of laboratory and natural breeders did not differ significantly.

As reproductive allocation (Grémare 1986) and clutch size (Nozais et al. 1997) seemed to be affected by female biomass, we corrected for differences in maternal size with an ANCOVA, using female postparturition biomass as covariate. No significant differences were found when the relative clutches (i.e. eggmass volume and number of eggs per egg-mass) of the single early breeders offspring was compared with the relative clutches of the first offspring of laboratory and natural breeders, nor with their relative total clutches (Table 2). Thus, differences in the reproductive output among groups can be considered as a function of differences in maternal body size.

\section{DISCUSSION}

As predicted from in situ observations and experimental studies, changes in the energy input for recently settled Eupolymnia nebulosa juveniles led to significantly different patterns of survival but similar individual growth patterns. Although our sample sizes in some cases were small, the high level of statistical differences between treatments provides strong evidence that these differences are real. Thus, limited food generated different intensities of interaction among juvenile worms, which were clearly reflected by differences in the distribution of tentacles within the individuals being fed on the different diets. In the case of the high-energy diet, the number of tentacles was similar for all survivors. For the low-energy diet, there was low survival and, among the survivors, a single individual bore more than half the total tentacles in the tank (as much as $57 \%$ at $t_{3}$ and $64 \%$ at $t_{12}$ ). Even at the end of the natural Mediterranean spawning period (i.e. at $t_{3}$ ), these results did not depend on the simulated recruitment strategies (i.e. recruitment of several successive pseudo-cohorts in the Mediterranean and single recruitment in the Atlantic). During the first months of benthic life, the juvenile dynamics gave rise to populations with the same tentacle distribution, regardless of the initial presence of individuals bearing a high number of tentacles. This finding supports the theory that the spawning period occurs in tandem with the spring rise in temperatures. For this reason the resulting homogeneity of the juvenile cohort joining the adult population at the end of this period (i.e. due to differential juvenile growth rates) has been seen as the main evolutionary constraint in the life cycle of Mediterranean E. nebulosa (see Bhaud et al. 1995). Moreover, the number of survivors was higher in the simulated Mediterranean recruitment strategy, suggesting that this strategy tended to increase the fitness of the native Mediterranean populations of the species.

Although the organic carbon content differed significantly between diets at the end of the experiment, the differences between sediment characteristics were certainly less than expected in the absence of worms. This seemed to reflect the combined effect of experimental diets and the worms' feeding activity. At the population level, our results imply that energy-rich habitats are able to support higher densities and biomasses than energy-poor habitats, and, in addition, are able to support populations with a high number of tentacles. At the individual level, the high-energy diet tended to produce more individuals bearing a higher number of tentacles than the low-energy diet, but all the worms seemed to grow to a similar size irrespective of food intake. This observation supports the idea that differences in food limitation tend to be compensated by individual interactions and, thus, that a natural population's structure and dynamics depend heavily on the availability of food. Furthermore, the individual reproductive response will also be influenced by food limitations.

The negative trade-off between growth and reproduction is probably the most clearly demonstrated phenotypic trade-off (Stearns 1994). Investment in reproductive activity may reduce growth and thereby future reproductive success, leading to larger organisms which produce more offspring than smaller organisms (Stearns 1994). In our experiment, however, differences in offspring were qualitative (i.e. to reproduce or not to reproduce), rather than quantitative (i.e. to reproduce more or to reproduce less). This extreme result was probably caused by our experimental design, which introduced food as a limiting factor. Females held under low-energy conditions did not reproduce during the first year of life, whereas $56 \%$ of the 'physiologically' mature females held under highenergy conditions did. Our methods meant that the remaining females $(49 \%)$, like females with oocytes on the low-energy diet, would delay reproduction for $1 \mathrm{yr}$. In natural conditions, these oocytes remaining inside the coelom would probably be used to fuel metabolism (i.e. oosorption), as occurs after the failure to release eggs among various species of polychaetes (Olive et al. 
1981, Gentil et al. 1990). The failure of some females held under high-energy conditions to reproduce may be caused either by differences in individual performance (see van Noordwijk \& de Jong 1986) or by a control mechanism at the population level. This would be an interesting subject for further study. Diet had an effect not only on the earlier age at maturity, but on the subsequent reproductive traits as well. Early breeders produced clutch sizes of about $1 / 7$ the size of those produced by laboratory and natural breeders. However, these differences are wholly attributable to differences in maternal body size (Table 2). Furthermore, the number of egg-masses per spawning period produced by each female correlated positively with maternal body size (Nozais et al. 1997). This agreed with the observation that early breeders produced only 1 egg-mass per female under our experimental conditions.

Additional costs may influence the reproductive success of the Mediterranean Eupolymnia nebulosa. Cocoon materials seem not to be metabolically costly (i.e. water plus some molecules of glyco-polysaccharids). Part of the energy resources, however, must be allocated to the mucous glands to guarantee the production of cocoons, which increases the sources of individual variability. The absence of reproduction when food was limited may be caused by the combined effect of the lack of resources allocated to the gonads and the inability of young worms to produce the jelly cocoons (i.e. mucous glands absent or not completely developed). Moreover, as occurs in other brooding sessile marine invertebrates (Lindquist \& Hay 1996), larvae might be chemically defended (again, a very interesting subject for further study) and chemical defences may also be costly in metabolic terms (Fagenström et al. 1987, Turón et al. 1996)

Two models of reproductive allocation have been proposed for polychaetes. The first model (Fig. 4A) has been described for, among others, opportunistic species such as Capitella sp. (Tsutsumi et al. 1990). This model implies the investment of energy in somatic growth until a minimum reproductively competent body size is reached. Then, allocation to the gonadic compartment may start. This model gives rise to similarly sized, mature individuals having different ages at first maturity according to the availability of food. A second model linking age at first reproduction to growth rates has been proposed for semelparous polychaetes such as nereids (Olive et al. 1986). In conditions of high growth rates, maturity may be reached in the first year. When growth rates are slower, reproduction may be delayed for 1 or more years. The final size of delayed breeders at spawning may then be larger than that of individuals maturing in the first year. By this time, however, mature individuals would be larger than non-mature individuals (Fig. 4B).
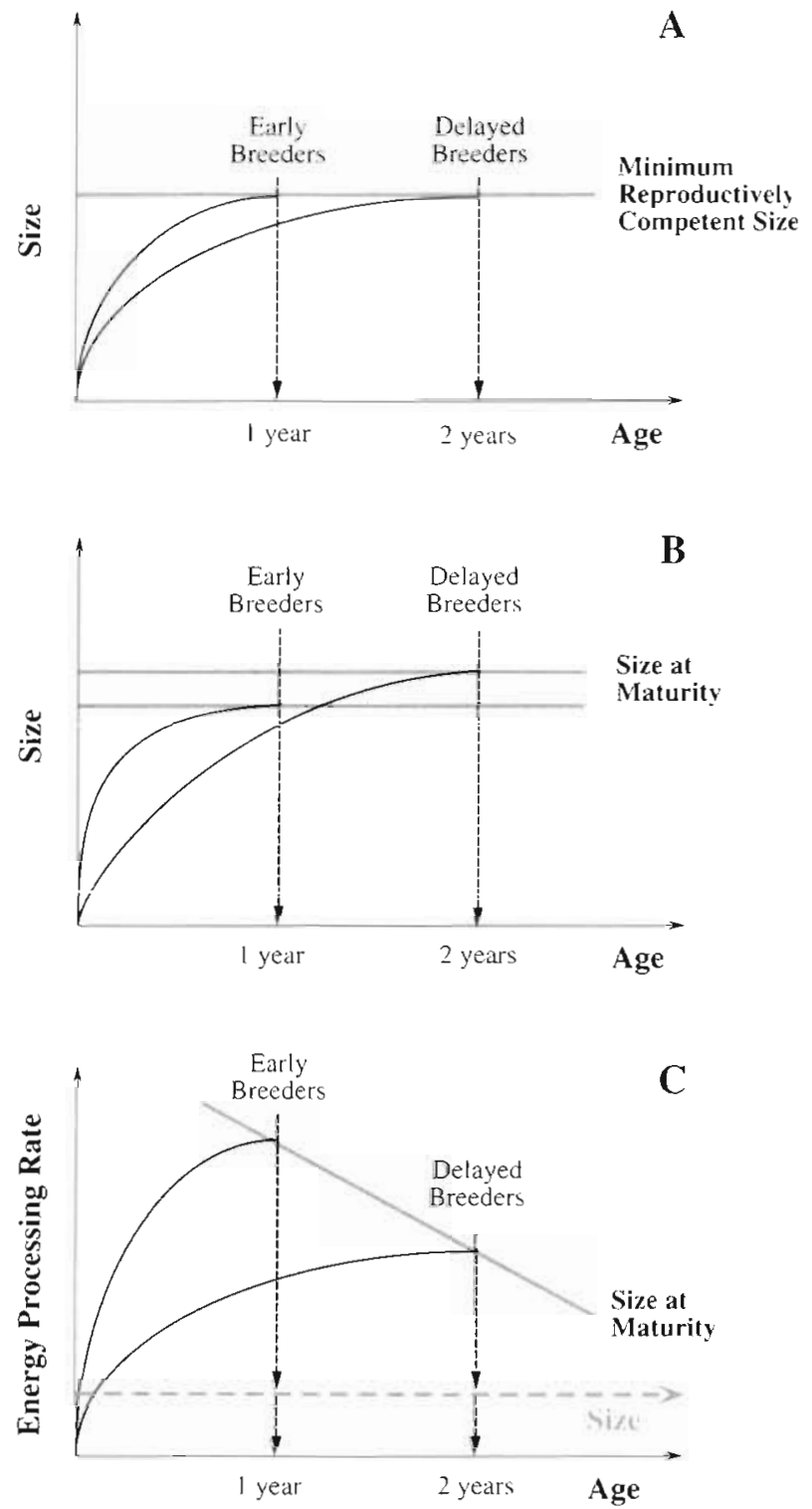

Fig. 4. Regulation models for age at first maturity in polychaetes. (A) Maturity starts after reaching a minimum reproductively competent body size. (B) Maturity depends on growth rates. (C) Maturity depends on external energy processing rates. In ( $\mathrm{C}$ ) the size axis is considered to be parallel to the age axis; thus, all 1 yr old individuals have the same size. Grey lines: body size at maturity for each type of breeder. Dashed grey arrow: size axis

In Eupolymnia nebulosa, the mean individual biomass did not differ between diets, but only the females held under high-energy conditions were able to reproduce. Moreover, they bore more tentacles than the females held under low-energy conditions. This was directly related to higher collecting efforts. According to these results, we are able to propose a third model which depends on the rate of energy intake (Fig. 4C). 
At low intake rates, all energy inputs are allocated to the somatic compartment. Conversely, high intake rates give rise to supplementary inputs that may be allocated earlier to the reproductive compartment (i.e. gonads and mucous glands), leading to an earlier age at first maturity. Thus, females at first reproduction may be older and larger at lower intake rates than at higher intake rates, but the size of both mature and non-mature females in their first year of life may be the same.

It has been suggested that reproductive differences between Eupolymnia nebulosa populations are the consequence of variable reproductive outputs (Grémare 1986). In fact, the reproductive allocation in Atlantic worms was almost double that in Mediterranean populations, whereas the maximum fecundity observed in the field was about 3 times higher in the former (authors unpubl.). In addition, Mediterranean environments, such as the Bay of Banyuls, provide difficult conditions for recruits after release, in spite of the protection of early larval development provided by the egg-masses (physical, linked to the mucous nature of cocoons, or chemical, linked to the presence of toxic or deterrent substances). As the strength of the relation between juvenile growth and survival increases, i.e. as conditions deteriorate for juveniles, maturity tends to be delayed (Stearns 1994). This suggests that the reproductive tactics exhibited by the Atlantic and the Mediterranean natural populations of $E$. nebulosa may not be due to genetic differences but rather to environmentally induced differences (i.e. the energy intake and/or the distribution pattern of adult habitat). At the energy-rich Atlantic sites, a free-spawning E. nebulosa matures during the first year of life and produces large offspring whereas, at the energy-poor Mediterranean sites, a brood-care E. nebulosa delays maturity and produces cocoons which will reduce larval dispersal. Therefore, it might be the case that, under the spatialand food-limited conditions of the Mediterranean, the selection of such an ecotype will result in an increase in fitness which compensates for the loss of fitness attributable to a generation time longer than and an offspring production lower than those of the Atlantic ecotype.

The existence of different life history traits has often been at the basis of the definition of sibling species among polychaetes (Grassle \& Grassle 1976, Wilson 1983, Bastrop et al. 1995). Nevertheless, genetic analysis of Atlantic (English Channel) and Mediterranean (Bay of Banyuls) Eupolymnia nebulosa specimens did not reveal major differences, at least in the RNA fragments studied (Lenaers \& Bhaud 1992). However, both life history strategies have never been found to occur within the same population, and distinct populations are maintained through time, suggesting our basic lab- oratory results are relevant to field conditions. Unfortunately, Atlantic E. nebulosa kept under Mediterranean conditions seemed unable to spawn naturally (Martin et al. 1996), while demographic data on E. nebulosa in the field are virtually non-existent. Thus, while it would be highly interesting to compare further the strategies and relative fitness of the Atlantic and Mediterranean populations under different food conditions, we cannot yet determine how these might affect survival and fitness in natural populations.

Our data provide evidence that the age at first reproduction in Mediterranean Eupolymnia nebulosa can be modified by diet. However, we suggest that factors other than the energy budget (i.e. the spatial constraints related to the presence of egg-masses; see Arnoux et al. 1995) may be fixed and thus linked to the maintenance of the 2 separate life history strategies. Therefore, we also suggest that the production of eggmasses might have evolved relatively recently as part of the adaptation of the species to Mediterranean habitats.

Acknowledgements. For assistance in the laboratory, we are indebted to M. J. Nattero. We thank A. Gordoa, T. Granata, A. Davis and $D$. Rosell for insightful comments on the manuscript. This paper is a contribution to the projects PNDR (France - GLOBEC) and AMB94-0746 (CICYT of Spain) and to the Associated European Laboratory of Marine Sciences (LEA). The first author was supported by a MEC/MRS grant (ref. no. fr93 46037786) and a research contract from the CSIC of Spain. The remaining authors were supported by a grant from the CNRS and the IFREMER of France.

\section{LITERATURE CITED}

Arnoux S, Bhaud M, Cazaux C, Cha JH, Duchêne JC, Fraunie P, Marcano G, Martin D, Nattero MJ, Nozais C, Pinedo S, Rey C, Sardá R (1995) Recruitment in light of biologicalphysical interactions in coastal waters: results of PNDR action at the Arago Laboratory in 1994-1995. Vie Milieu 45:85-105

Bastrop R, Röhner M, Jürss K (1995) Are there two species of the polychaete genus Marenzelleria in Europe? Mar Biol 121:509-516

Ben-Tuvia A (1983) The Mediterranean Sea. B. Biological aspects. In: Ketchum BH (ed) Ecosystems of the world, Vol 26. Estuaries and enclosed seas. Elsevier, Amsterdam, p $239-248$

Bhaud M, Cha JH (1994) Larvae-substrate relationships of Eupolymnia nebulosa Montagu, 1818 (Polychaeta, Terebellidae): an experimental analysis. Mem Mus Natl Hist Nat Ser A Zool 155:111-222

Bhaud M, Cha JH, Duchene JC, Martin D, Nozais C (1995) Larval biology and benthic recruitment: new ideas on the role of egg-masses and modelling life-cycle regulation. Sci Mar 59:103-117

Bhaud M, Grémare A, Lang F, Retiere C (1987) Comparative study of reproductive features of Eupolymnia nebulosa (Montagu) (Polychaeta, Terebellidae) in two parts of its distributional area. C R Hebd Séanc Acad Sci Paris 304: $119-122$ 
Boggs CL (1992) Resource allocation: exploring connections between foraging and life-history. Funct Ecol 6:508-518

Buscail R, Pocklington R, Germain C (1995) Seasonal variability of the organic matter in a sedimentary coastal environment: sources of gradation and accumulation (continental shelf of the Gulf of Lion, NW Mediterranean Sea). Cont Shelf Res 15:843-869

Cha JH (1994) Analyse expérimentale du recrutement benthique chez Eupolymnia nebulosa (Annélide Polychète Terebellidae) en Méditerranée Occidentale. Doctoral thesis, Univ P et M Curie (Paris VI), Banyuls-sur-Mer

Cha JH, Bhaud M, Nattero MJ (1991) Etude expérimentale du recrutement benthique en canal hydrodynamique et en milieu calme. C R Acad Sci Paris 313:113-118

Duchêne JC, Nozais C (1992) Etude de l'émission des stades larvaires précoces d'Eupolymnia nebulosa (Polychaeta: Terebellidae). Ann Inst Océanogr Monaco 68:15-24

Fagenström T, Larsson S, Tenow $\mathrm{O}$ (1987) On optimal defence in plants. Funct Ecol 1:73-81

Gentil F, Dauvin JC, Ménard F (1990) Reproductive biology of the polychaete Owenia fusiformis Delle Chiaje in the Bay of Seine (eastern English Channel). J Exp Mar Biol Ecol 142:13-23

Grassle JP, Grassle JF (1976) Sibling species in the marine pollution indicator Capitella (Polychaeta). Science 192: $567-569$

Grémare A (1986) A comparative study of reproductive energetics in two populations of the terebellid polychaete Eupolymnia nebulosa Montagu with different reproductive modes. J Exp Mar Biol Ecol 96:287-302

Grémare A (1988) Aspects quantitatifs de la reproduction chez quelques annelides polychètes: interêts et perspectives. Tome 1. Doctoral thesis, Univ P et M Curie (Paris VI), Banyuls-sur-Mer

Guille A (1970) Bionomie benthique du plateau continental de la côte catalane française. II. Les communautés de la macrofaune. Vie Milieu 21:149-280

Keddy PA (1989) Competition. Population and community biology series. Chapman and Hall, New York

Ketchum BH (1983) Estuarine characteristics. In: Ketchum BH (ed) Ecosystems of the world, Vol 26. Estuaries and enclosed seas. Elsevier, Amsterdam, p 1-13

Lang F (1984) Etude de l'activité tentaculaire de Eupolymnia nebulosa Montagu (Annélide, Polychète): son rôle sur la dinamique de la population et la structuration du peuplement. Oceanis 10:775-784

Editorial responsibility: Otto Kinne (Editor),

Oldendorf/Luhe, Germany
Lang $F$ (1986) Peuplement des fonds durs du bassin maritime de la Rance; rôle fonctionnel de Eupolymnia nebulosa (Annélide Polychete). Doctoral thesis, Université de Rennes I, Dinard

Lenaers G, Bhaud M (1992) Molecular phylogeny of some polychaete annelids: an initial approach to the Atlantic-Mediterranean speciation problem. J Mol Evol 35: 429-435

Lindquist N, Hay MA (1996) Palatability and chemical defense of marine invertebrate larvae. Ecol Monogr 66: $431-450$

Martin D, Cha JH, Bhaud M (1996) Consequences of oocyte form modifications in Eupolymnia nebulosa (Annelida; Polychaeta). Invertebr Reprod Dev 29:27-36

Nozais C, Martin D, Cha JH, Duchêne JC. Charles F, Grémare A (1997) Dynamics of egg production within each breeding season in Mediterranean populations of the terebellid polychaete Eupolymnia nebulosa. J Mar Biol Assoc UK 77:1027-1043

Olive PJW, Garwood PR, Bentley MG (1981) Oosorption and reproductive failure in Polychaeta in relation to their reproductive strategy. Bull Soc Zool Fr 106:263-268

Olive PJW, Grant A, Cowin PDB (1986) Decision and choice in polychaete reproductive cycles. In: Porchet $M$ (ed) Advances in invertebrate reproduction. Elsevier, Amsterdam, p $371-378$

Pérès JM (1985) History of the Mediterranean biota and the colonization of the depths. In: Margalef $\mathrm{R}$ (ed) Key environments: Western Mediterranean. Pergamon Press, Oxford, p 198-232

Ricklefs RE (1991) Structures and transformations of lifehistories. Funct Ecol 5:174-183

Stearns SC (1994) The evolution of life histories. Oxford University Press, New York

Tsutsumi H, Fukunaga S, Fujita N, Sumida M (1990) Relationship between growth of Capitella sp. and organic enrichment of the sediment. Mar Ecol Prog Ser 63:157-162

Turón X, Becerro MA, Uriz MJ (1996) Seasonal patterns of toxicity in benthic invertebrates: the encrusting sponge Crambe crambe (Poecilosclerida). Oikos 75:33-40

van Noordwijk AJ, de Jong G (1986) Acquisition and allocation of resources: their influence on variation of life-history tactics. Am Nat 128:137-142

Wilson WH Jr (1983) Life-history evidence for sibling species in Axiothella rubrocincta (Polychaeta, Maldanidae). Mar Biol 76:297-300

Submitted: June 16, 1997; Accepted: February 11, 1998 Proofs received from author(s): March 23, 1998 